\title{
CONCYTEC: Fostering and assessing science, technology and innovation in Peru
}

What motivated the organization of the Hatun Tinkuy Peru [1] event, the great gathering for scientific research and production?

When I started working at the Peruvian National Council of Science, Technology and Technological Innovation (CONCYTEC, original Spanish-language acronym) [2], I was given the main task of assessing the platform where national researchers' CVs are registered, which was called the National Directory of Researchers and Innovators. We did that in 2017 and we then planned a new project, the Peruvian Current Research Information System (PeruCRIS), of which we will talk about more in detail later.

In 2018, we noticed that our national repository, Open Access to Scientific Information for Innovation (ALICIA) [3], which harvests records from other repositories, had some issues, which led us to start some projects for improving the metadata from our researchers', research and of some repositories; these projects are still ongoing. I also noticed that Peruvian journals had several challenges. CONCYTEC is Latindex's collection center in Peru and it also manages the SciELO Peru website [4]. Well, it turned out that Peruvian journals lacked promotion and so I met with a group of journal editing and bibliometric analysis experts to tell them that I wanted to improve our scientific communication capabilities because I noticed some other issues that prevented us from going further. That was when we came up with the idea of organizing a large conference, which would serve as an inspiration to everyone who currently edits or wants to edit journals; for everyone who knows how to do it also to share detailed knowledge on the technical and academic issues involved in the production of scientific journals. Moreover, we also wanted to invite the main companies involved as stakeholders: scientific information providers and publishers.

That is how we came up with this idea of the Hatun Tinkuy conference, which we held in 2019 [5]. I must confess that I am not an expert; I graduated as a computer engineer. I have previously published in some journals while I was studying my doctorate program, but I have never edited one. Therefore, to call the professionals is what should be done. We gathered with a large group of people to define guest speakers and topics and some colleagues from the CONCYTEC and from other Peruvian institutions advised us about the topics to be covered by the speakers; I wanted for open science to have a prominent space on the agenda. I also wanted to see how Latindex was used in other countries and so we had guest speakers from Costa Rica and Chile to tell us about it. I also wanted to have topics such as how to edit a journal and how to detect plagiarism. We held conferences and workshops

Erratum: It has come to the attention of the publisher that the article, Melgar, A. and MachinMastromatteo, J.D. (2020), "Editorial”, published in Digital Library Perspectives, Vol. 36 No. 3, pp. 213-217, was incorrectly labelled as an Editorial and did not feature the correct article title. These errors were introduced in the editorial process and have now been corrected in the online version. The publisher sincerely apologises for this error and for any inconvenience caused.

When citing this article, please cite: Melgar A. and Machin-Mastromatteo J.D., (2020), "CONCYTEC: Fostering and assessing science, technology and innovation in Peru" published in Digital Library Perspectives, Vol 36 No. 3, pp. 213-217. https://doi.org/10.1108/DLP-08-2020-052.

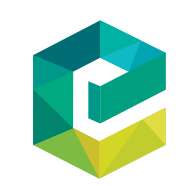

Digital Library Perspectives Vol. 36 No. 3, 2020 pp. $213-217$ (c) Emerald Publishing Limited DOI 10.1108/DLP-08-2020-052 
DLP 36,3

214

on those and more specific topics that, I think, were very interesting for the people who attended.

The conference had all of the important topics for scientific production, research and journal editing; and regarding the international guest speakers and the audience, the gathering was a sort of a who is who in the field of information science at the Ibero-American stage. We have the idea of repeating this event every two years. I would like to consolidate two events for CONCYTEC. The first event would be the PeruCRIS conference in 2018, of which we would have the second edition in 2020 [6]. In 2021, we should be doing the second edition of Hatun Tinkuy. To be honest, the main purpose was to make an event for Peruvians, so I was surprised to see people from Colombia, Panama, Honduras, Chile, Argentina; that said a lot about the quality of the guest speakers. I am happy for how the conference turned out and I believe we accomplished our goals. We also made good friends in the event. I think this is an important milestone for Peru; now, we need to continue building and working from it.

At CONCYTEC, we are reformulating the management of SciELO Peru; we are going to designate an advisory board of SciELO and a technical secretariat; we are going to increase scientific communication and dissemination activities, and we now have some ideas for helping journal editors: we want to establish a permanent seminar for them, similar to the experience of the National Autonomous University of Mexico. This will be a space for learning about current topics that are relevant for journal editing, especially in the field of open science and specifically we need to deepen our knowledge on research evaluation in the context of open science. This is something that we are studying a lot about to develop a method for evaluating researchers that takes into consideration open science. During the conference, we heard about alternate metrics (altmetrics) and also about criticisms toward the famous impact factor for journals. Hatun Tinkuy represented a milestone for Peru, and I truly hope that something similar can be done in other Latin American countries. Attendees from other countries really liked the conference and wished to replicate it in their countries. It is a kind of event that truly promotes and encourages attendants to work and improve their practices; it also enables the development of links between government, researchers and information services providers.

One of the things that I wanted to achieve with this conference was to also come up with a space where people could visit the stands that the information services providers had at the conferences and also to enable spaces for attendees to talk to the guest speakers (e.g. at coffee breaks). I enjoyed seeing how people approached speakers, asked them questions and exchanged emails after each presentation or workshop. I think that all the presentations and workshops were very valuable. The recordings from presentations and workshops are available at YouTube [7] and all the slides are at CONCYTEC's repository [8]. One of the greatest benefits I see is that the attendants could go back home with new contacts and ask further questions. That is another goal we have accomplished too. We are very happy, this has been the first major event of its kind organized in Peru, and we are going to continue doing it. That is our commitment to the country.

\section{Peru has been developing a current research information system at a national level, please tell us about it}

PeruCRIS [9] is a big project with a series of challenges we need to pull off. When I received the call to take charge of the evaluation and knowledge management direction, they asked me to improve the platform that we had in CONCYTEC. When we made the first analysis at the technical level, we noticed the usual problem of "software isles", where all the systems we had did not communicate among themselves. That is where we started, from a technical problem. Then, we dug more into the systems and we noticed that our data model did not follow a standardized system and there were also issues with persistent identifiers. It was a 
system created only for Peru. So, obviously, there were interoperability issues because the systems could not communicate among themselves or with other systems. When the new CONCYTEC President, Dr Fabiola León Velarde took office, she asked me to conduct a complete analysis to identify our national needs and the state of the institutions in the country in terms of scientific, technological and innovation (STI) management and research. We visited 50 public and private universities as well as research institutes, we participated in OCLC's and EuroCRIS' survey, where Peru contributed $10 \%$ of the responses to the survey, dominating the responses from the South/Central American and Caribbean region; as a large number of Peruvian institutions "are implementing an in-house system to work in conjunction with a DSpace or DSpace-CRIS implementation” (Bryant et al., 2018, p. 22).

We noticed that we needed to organize our data and information to understand the basics: who is who. Who does research in Peru and in which areas? Which projects get funded? What kinds of equipment do we have in the country? So, that was when we started with the idea of making the PeruCRIS project, which was supported by the Peruvian legal framework on STI, which states that CONCYTEC must provide a scientific information network on topics related to STI. In a broad sense, that is the purpose of PeruCRIS and we have made some progress in this area. First, CONCYTEC runs ALICIA and $100 \%$ of our universities already have an institutional repository, so ALICIA harvests records from them. However, we found the issue that our metadata did not have the necessary quality to produce appropriate bibliometric indicators. Therefore, we started to conceive everything as a big project where repositories are an essential source of data for PeruCRIS. We are about to launch new guidelines for improving ALICIA's metadata, and hence enable the production of indicators; so, we can properly identify important fields such as authors' names, thesis advisors' names, persistent links, and in general working to normalize many fields using URIs. Our team has also worked with semantic Web issues, given the fact that the common problems originated from years of manual input without an appropriate authority control.

Currently, we have a pilot with five Peruvian institutions that are working on customizing the DSpace-CRIS, for profiling the future national platform (PeruCRIS profile), which is based on the European standard CERIF-XML. When we started this project, we contacted EuroCRIS, because they have been working with this type of systems for many years; so, they put us in touch with other countries. We have had many conferences with people from Italy, England and Spain to know more about their experiences and learn from their mistakes. Can you imagine starting a project of this magnitude from scratch? That was impractical. That is how we developed that fellowship. We have agreements with EuroCRIS and also with DuraSpace. We follow and participate in Duraspace governance model because all our repositories are in DuraSpace. Then, we have campaigns for normalizing data. Clarivate Analytics has been along with us to help normalize every institution in Web of Science (WoS) and we hope to do the same with Scopus. Moreover, last year we launched a national-level campaign with ORCID to use it as a persistent identifier and have a sort of a census of how many institutions and researchers we have. Thanks to that campaign, we have noticed an increase in our numbers. Currently, there are about 26,000 researchers with an ORCID and for them to be registered allows a conducting a more proper information management.

Something worth to emphasize about PeruCRIS is that the CONCYTEC is assuming the responsibility of data gathering. The reason behind this is that, every time that I travel abroad and meet with other colleagues and researchers, they state that the main problem is that researchers spend too much time updating the information in their CVs, and it is common for researchers to be required to manually fill out several $\mathrm{CVs}$ and profiles for different organizations and purposes. That is not an exception here. I myself spend a lot of time doing it. Our vision consists on developing a system that will work within a common data framework, 
DLP

36,3

216

one that follows international standards, is interoperable, and operates under the best practices. This represents a change of paradigm in which we will not be requiring authors to input their data in yet another system, but CONCYTEC is going to conduct the data collection, from primary sources, and then we will hand it over to the universities. For instance, the identification of authors is being conducted in an interoperable manner with the National Registry of Identification, academic degrees are gathered through the National Superintendence of Education (SUNEDU), and the publication date, at least on an initial stage, will be gathered from WoS and Scopus; but the idea is to also include other databases that allow CONCYTEC the possibility of harvesting and importing such data. Data about patients will be gathered from the National Institute for the Defense of Free Competition and the Protection of the Intellectual Property (INDECOPI). We are proposing a very efficient solution with this paradigm because we are talking about existing data and we are then streamlining the data gathering processes by enabling data interoperability and exchange throughout all the systems that already have researchers' data.

In the current environment, each university has to send research data to the Ministry of Education (MINEDU), SUNEDU, CONCYTEC and even to other departments in the same university. They normally have to manually fill out many formats to send this information and usually they exchange the same data, but structured in different ways; hence, work is duplicated. This is perhaps one of our major challenges: to make the system more efficient; but we have workgroups with SUNEDU and MINEDU to enable data exchange among our systems. For instance, if MINEDU needs research data, our goal is that CONCYTEC can provide it through the interoperability among our systems. We are working right now on a common format of indicators for institutions, so there will not be the need of asking for additional data. This is an issue that we can resolve through an appropriate implementation of technology, so that technology facilitates data recording, gathering and exchange, thus preventing researchers and institutions to continuously prepare several reports about the same data.

There is another relevant component, which is related to library and informational science and its professionals. It is important to highlight the role of information scientists because they are the ones who know about and work with topics such as thesauri, taxonomies, information architecture and authority control. So, it is important to count on these experts to help us manage these informational science issues and generate data of quality; because without data of quality, there is nothing. This is why the team at CONCYTEC includes several information professionals and computer experts.

Another topic is the issue of management. We need to manage, to look outside our borders, to consider the best practices at an international level, we have to talk to and invite other people. In this aspect, the current administration of CONCYTEC has outdone itself. We have organized had various events in Peru where prominent figures have participated, such as PeruCRIS (2018) and Hatun Tinkuy (2019) with which we have gathered the best international experiences to help us build this system. That may be the most beautiful experience of this because you take computer science, informational science, you add management and the result of this particular sum is the PeruCRIS project; an enormous challenge that takes time to develop. We need to work within CONCYTEC and with each university. In fact, recently, San Ignacio de Loyola University presented the first institutional CRIS [10], becoming the first Peruvian university to have developed a CRIS under international standards. We need to emphasize that such system exists thanks to the existence of a bibliometric unit within that of the USIL University (PachecoMendoza et al., 2020). Therefore, I believe that it is important to count with the support and skills of informational science experts, as well as with an administration that understands the importance of the research data management at the universities, because we can use such data for holding professor-promotion contests, making universities' work more public and visible, 
and for us at CONCYTEC, if the universities implement their CRIS, it means that we have valuable partners for gathering and storing research data as primary sources. That is part of the idea, if each university implements its own CRIS, it will help us manage the data and information that Peru needs for planning and for developing our priority areas. PeruCRIS is not CONCYTEC's system, it is a system at the service of the Peruvian state. Therefore, the next step is more political, as it would consist of establishing a working group that includes not only people from CONCYTEC but also from other state and private organizations. They will help manage the platform and tell us which kinds of services should the CRIS offer, so data and information can follow a more efficient cycle and be more useful for all stakeholders. In the information society, if knowledge is not reused, it loses its value. We have many things to do, but we have the goal of making PeruCRIS a system at the service of Peruvians.

\section{Consejo Nacional de Ciencia, Tecnología e Innovación Tecnológica, Lima, Peru, and Juan D. Machin-Mastromatteo Facultad de Filosofía y Letras, Universidad Autónoma de Chihuahua, Chihuahua, Mexico}

\section{Notes}

1. Hatun Tinkuy, in Quechuan language means large gathering.

2. https://portal.concytec.gob.pe

3. https://alicia.concytec.gob.pe

4. Latindex and the Scientific Electronic Library Online (SciELO) are Ibero-American level digital initiatives, the first one provides two catalogs, one of registered academic journals and the other a catalog of selected journals that have successfully passed Latindex's quality evaluations; while SciELO provides full text open access to the journals affiliated and there are sub-portals per country. See www.latindex.organdhttps://scielo.org/

5. https://entreparesperu.concytec.gob.pe

6. That was the original plan, but PeruCRIS 2020 had to be cancelled due to the COVID-19 pandemic.

7. https://youtu.be/QvnkcH6KnvU

8. All the slides by guest speakers are available at: http://repositorio.concytec.gob.pe/cris/events/ events00014

9. https://perucris.concytec.gob.pe

10. https://cris.usil.edu.pe

\section{References}

Bryant, R., Clements, A., Castro, P., Cantrell, J., Dortmund, A., Fransen, J., Gallagher, P. and Mennielli, M. (2018), "Practices and Patterns in Research Information Management: Findings from a Global Survey”, OCLC Research, Dublin, OH, available at: https://doi.org/10.25333/BGFG-D241

Pacheco-Mendoza, J., Alhuay-Quispe, J. and Machin-Mastromatteo, J. (2020), "Bibliometrics units as dynamic engines for universities' scientific production”, Information Development, Vol. 36 No. 2, pp. 301-305. 